\title{
Coline CARDI et Geneviève PRUVOST (dir.), Penser la
} violence des femmes

Paris, La découverte, 2012

Karine Lambert

\section{(2) OpenEdition \\ Journals}

\section{Édition électronique}

URL : https://journals.openedition.org/ahrf/13387

DOI : $10.4000 /$ ahrf. 13387

ISSN : 1952-403X

Éditeur :

Armand Colin, Société des études robespierristes

Édition imprimée

Date de publication : 1 décembre 2014

Pagination : 159-161

ISBN : 978-2-200-92928-2

ISSN : 0003-4436

Référence électronique

Karine Lambert, "Coline cardi et Geneviève pruvost (dir.), Penser la violence des femmes », Annales historiques de la Révolution française [En ligne], 378 | octobre-décembre 2014, mis en ligne le 01 décembre 2014, consulté le 01 juillet 2021. URL : http://journals.openedition.org/ahrf/13387 ; DOI : https://doi.org/10.4000/ahrf.13387

Ce document a été généré automatiquement le 1 juillet 2021.

Tous droits réservés 


\section{Coline CARDI et Geneviève PRUVOST (dir.), Penser la violence des femmes}

Paris, La découverte, 2012

Karine Lambert

\section{RÉFÉRENCE}

Coline CARDI et Geneviève PRUVOST (dir.), Penser la violence des femmes, Paris, La découverte, 2012, 441 p., ISBN 9782707172969, $32 €$.

1 L'ouvrage collectif, Penser la violence des femmes, dirigé par les sociologues Coline Cardi et Geneviève Pruvost rassemble les contributions du colloque éponyme qui s'était tenu en juin 2010 à l'Université Paris-7. En proposant à Arlette Farge de rédiger la préface de ce recueil de textes issus des nombreuses disciplines des sciences humaines et sociales (anthropologie, histoire, sociologie) ainsi que du champ des études en littérature, sciences politiques, linguistique, sciences juridiques, criminologie, Coline Cardi et Geneviève Pruvost placent d'emblée leur entreprise dans la filiation des travaux pionniers que celle-ci a rassemblés dans les années 1990 avec Cécile Dauphin et qui ont abouti à l'essai De la violence et des femmes, Albin Michel, 1997.

2 L'actualité médiatique de cette dernière décennie, qui a régulièrement porté à sa Une des infanticides multi récidivistes, des bandes de filles coupables d'actes barbares, des kamikazes, des cheffes de clans mafieux, des femmes mourant sur les coups de leurs compagnons ou victimes de viols collectifs a rendu plus impératif l'urgence de penser la violence des femmes, d'instiller dans les interstices de l'ordre social de l'hétérogène, de la singularité, loin des discours communs oscillant entre les stéréotypes de femmes victimes et de femmes monstres.

«Exhumer, dénaturaliser, contextualiser, historiciser, repolitiser la violence des femmes, tel est l'objet de ce livre » (p.13). Afin d'atteindre cet ambitieux objectif tout en évitant la juxtaposition d'études de cas relevant de temporalités ou d'espaces socioculturels divers, les coordinatrices proposent en introduction d'inscrire les différents 
chapitres dans un cadre épistémologique et théorique qui constitue une remarquable contribution à la réflexion sur la violence dont elles proposent une définition performative, et une évaluation convaincante du genre comme catégorie d'analyse. En effet, l'enjeu de cette entreprise est $d$ '«interroger l'ordre social que sous-tend l'assignation majoritaire des femmes à la position de l' "a-violence" ", (p. 56).

Cardi et Pruvost proposent ainsi, dans la continuité du numéro de la revue en ligne Champ pénal (Vol. VIII, 2011), intitulé "Le contrôle social des femmes violentes ", qu'elles ont également coordonné, une analyse en trois phases: "la violence des femmes "hors cadre", la violence sous tutelle, la violence d'émancipation » (p. 16).

5 Peuvent dès lors être répertoriés les processus de déni, d'invisibilisation, de nonreconnaissance, d'oubli qui sont à l'œuvre et qui permettent d'interroger «le déni d'antériorité ", concept forgé par Delphine Naudier à propos des femmes écrivains dont on ne cesse de fêter l'arrivée sur le marché éditorial alors que leur présence est constante. Cardi et Pruvost proposent avec justesse d'appliquer ce même raisonnement aux femmes violentes. Ainsi, seule une historicisation rigoureuse de la participation des femmes à la criminalité, aux émeutes, aux batailles permet de déconstruire des phénomènes présentés comme inédits, tels les gangs de filles (Niget, Duprez). Les auteures abordent également la responsabilité du mouvement féministe dans la minoration de la violence féminine en raison de la nécessaire «hiérarchie dans les luttes féministes » tout en soulignant la nécessité d'approfondir les recherches, encore trop rares, portant sur « l'histoire des rapports entre luttes féministes, violences des femmes, avec des comparaisons internationales » (p. 27).

Dans une perspective autre, celle d'une recension des mises en récits typiques, il apparaît que la subordination des violences féminines à celles commises par les hommes opère comme une « mise sous tutelle » qui prive les femmes de leur agency, de leur capacité d'agir, de leur statut de sujet autonome. Les auteur/e/s mettent à jour les mécanismes qui sans cesse réagencent la domination masculine: les femmes sont réputées exercer leurs actes sous l'emprise de leurs émotions (Bugnon), de la manipulation (Dayan). La portée de ces actes est minorée (Lelièvre, Léonard), sousévaluée (Baraduc), considérée comme non susceptible de modifier l'ordre des sexes. La domination masculine est justifiée par certains discours criminologiques (Lumbroso et Ferri), ethnocentriques, biologisants, pathologisants qui ensauvagent une nature féminine qu'il conviendrait dès lors de placer sous contrôle.

7 Le troisième "grand récit " analysé ouvre sur un renversement de l'ordre social en permettant l'accession des femmes au pouvoir ou à « l'indifférenciation égalitaire » (P. 38). La famille (Feldman), l'école, le sport, les forces armées (Freedman), l'espace public, la fiction cinématographique (Fassin, Molia) ou littéraire (Guidée) constituent ainsi des terrains où s'enracinent des transgressions subversives, individuelles ou collectives, souvent temporaires, potentiellement porteuses d'émancipation. Néanmoins, précisent les directrices de l'ouvrage, «si l'égalité des sexes [...] y compris celui du pouvoir de la violence, constitue une condition de l'égalité [...], la violence ne constitue pas [...] la voie souhaitable pour obtenir l'égalité » (p. 56).

8 Les vingt-trois chapitres de l'ouvrage sont structurés autour de quatre thèmes traités dans une perspective transnationale et transpériode, (Violences politiques/Le privé et le politique/Traitement institutionnel de la violence des femmes/Figurations et défigurations des femmes violentes). Dominique Godineau, Marie-Élisabeth Handman, Claudine Parent et Éric Fassin ont respectivement pris en charge l'introduction d'une 
partie, ce qui renforce la cohérence de l'ouvrage. Le premier axe présente de nombreuses configurations de la participation féminine aux conflits collectifs depuis l'Ancien Régime (Dufournaud, Chevalier), la Révolution française (Martin) jusqu'aux luttes armées contemporaines de la Palestine (Dayan-Herzbrun), au Pérou (Boutron, Felices-Luna). La présentation chronologique des articles rend plus perceptible encore l'impérative nécessité d'une contextualisation fine. Les normes sociales, les notions de ce qui est tolérable, d'honneur, de courage, de virilité qui participent du contrôle social doivent être interrogées tant elles permettent de (re) qualifier et classifier les violences féminines.

9 La deuxième partie met en visibilité des figures incarnées de la violence féminine s'exerçant dans des contextes marqués par la domination masculine: la pédophile nécessairement impensable tant elle questionne l'ordre hétéronormé (Bourge), la scandaleuse Violette Morris (Bonnet), les cheffes de gangs brésiliens (Duprez). Certain/e/s auteur/e/s invitent à poursuivre les recherches sur des terrains encore insuffisamment investis tels les sociétés matrilinéaires (Handman), les violences domestiques ou conjugales commises entre femmes (Watremez) ou les usages stratégiques féminins de la force physique (Lebas).

Un même souci anime les contributeur/trice/s des deux derniers axes : questionner les sources, débusquer les silences ou les absences (Mazeau), déconstruire les discours et les catégories (Lelièvre, Léonard), interroger les postures des chercheurs, veiller à conserver une grande vigilance méthodologique et se garder des mots (Lagorgette) et des représentations de "la femme criminelle " (Kaluszynski), d'un éternel féminin monstrueux, des figures mythiques ou stéréotypées (amazones, sorcières, furies, virago). Ceci est tout particulièrement perceptible lorsqu'il s'agit de débusquer les mécanismes d'exclusion des femmes hors du champ politique.

11 Chaque article permet de mesurer la complexité des réalités singulières et collectives, le foisonnement des chantiers en cours, la multiplicité des (en) jeux de pouvoirs qui enserrent "la nature féminine", le corps des femmes, pour tenter de disqualifier, déresponsabiliser, occulter, instrumentaliser la participation féminine à l'exercice de la violence, tant cette dernière questionne et perturbe l'ordre des sexes.

Enfin, ce livre justement qualifié d'« événement scientifique " par Rose-Marie Lagrave dans sa postface ne se contente pas de sonder les violences des femmes mais apparaît au total comme programmatique en raison de sa volonté de mettre au jour la complexité de la violence des femmes et de la penser au prisme du genre et de la multiplicité des pistes de recherches ouvertes. 